\title{
Chromosomal imbalances are associated with metastasis-free survival in breast cancer patients
}

\author{
Michaela Aubele ${ }^{\mathrm{a}, *}$, Gert Auer ${ }^{\mathrm{b}}$, Herbert Braselmann ${ }^{\mathrm{c}}$, Jörg Nährig ${ }^{\mathrm{d}}$, Horst Zitzelsberger $^{\mathrm{c}}$, \\ Leticia Quintanilla-Martinez $^{\mathrm{a}}$, Jan Smida ${ }^{\mathrm{d}}$, Axel Walch ${ }^{\mathrm{d}}$, Heinz Höfler ${ }^{\mathrm{a}, \mathrm{d}}$ and Martin Werner ${ }^{\mathrm{d}}$ \\ ${ }^{\text {a }}$ GSF - Research Center for Environment and Health, Institute of Pathology, D-85764 Neuherberg, Germany \\ ${ }^{\mathrm{b}}$ Institute of Radiobiology, D-85764 Neuherberg, Germany \\ ${ }^{\mathrm{c}}$ Department of Oncology and Pathology, Karolinska Institutet and Hospital, S-17176 Stockholm, Sweden \\ ${ }^{\mathrm{d}}$ Technische Universität, Institute of Pathology, D-81675 München, Germany
}

Received 28 February 2002

Accepted 30 May 2002

Abstract. Multiple chromosomal imbalances have been identified in breast cancer using comparative genomic hybridization (CGH). Their association with the primary tumors' potential for building distant metastases is unknown. In this study we have investigated 39 invasive breast carcinomas with a mean follow-up period of 99 months (max. 193 months) by CGH to determine the prognostic value of chromosomal gains and losses.

The mean number of chromosomal imbalances per tumor was $6.5 \pm 0.7$ (range 2 to 18). The most frequent alterations identified in more than $1 / 3$ of cases were gains on chromosomes 11q13,12q24,16,17, and 20q, and losses on 2q and 13q. A significantly different frequency of chromosomal aberrations $(p \leqslant 0.05)$ was found between DNA-diploid and non-diploid tumors (gain on chromosome 17). Differences were also noted between tumors progressing to distant metastases within the period of follow-up and those which do not (gains on 11q13 and 12q24; loss on 12q).

Significant univariate correlations $(p \leqslant 0.05)$ with the metastasis-free survival of patients were found for lymph node status, the cytometrical determined DNA ploidy (diploid/non-diploid) and anisokaryosis, and for DNA gains on 11q13, 12q24, 17, and 18p. An unexpected inverse correlation was found between clinical outcome and gains on 11q13 and 12q24.

In multivariate analysis independent prognostic value, in addition to lymph node status, was found for chromosomal gains on $11 \mathrm{q} 13,12 \mathrm{q} 24,17$ and 18p. Amplification on 20q, which did not correlate with metastasis-free survival in a univariate analysis, showed weak prognostic significance in combination with the nodal status.

The prognostic value of chromosomal alterations - some of them by inverse correlation - suggests an interaction and/or compensation of the involved amplified genes and their effects on the occurrence of distant metastases in breast cancer patients.

Keywords: CGH, prognosis, breast cancer, chromosomal imbalances, metastasis-free survival

\section{Introduction}

Breast cancer is the most prevalent cancer among women in industrialized countries. Classification and prognostication are traditionally based on histopathological parameters such as tumor grade, size, and

\footnotetext{
${ }^{*}$ Corresponding author: Dr. Michaela Aubele, GSF - Forschungszentrum, Institut für Pathologie, Ingolstädter Landstrasse 1, 85764 Neuherberg, Germany. Tel.: +49 893187 4132; Fax: +49 893187 3360; E-mail: aubele@gsf.de.
}

lymph node status. The most important selection criteria for adjuvant therapy are the presence or absence of tumor metastases in the axillary lymph nodes at the time of operation [17], steroid receptor status, and, more recently, HER2/neu overexpression [15,35]. In addition to these features, quantitative cytometric measurements including the rate of proliferation, DNA histogram type, and morphometric parameters such as anisokaryosis have been shown to provide additional prognostic criteria [1-3,14,24]. However, despite these developments, 20 to 30 percent of patients within the 
group of node-negative tumors, still die of disease, whereas a proportion of node-positive tumors do not proceed to distant disease [17]. Therefore, there is a growing need for more accurate prognostic factors that allow an individual therapy adaption.

The comparative genomic hybridization $(\mathrm{CGH})$ technique has been shown to be a very powerful tool for the screening of DNA copy number changes in tumor cells. A wide variety of chromosomal imbalances have been detected by $\mathrm{CGH}$ in invasive breast carcinomas $[6,18,23,28,36]$. Here an amplification on chromosomal region $20 \mathrm{q}$ has emerged as one of the most common genetic aberration [6,20,25,31]. In node-negative breast carcinomas DNA aneuploid tumors were shown to harbour more gains than diploid ones [17]. The authors concluded that these gains (in particular 8q, $11 q 13,17 q$ and 20q) might be late, progression-related events, and may be associated with a more aggressive clinical behaviour. A significantly higher number of chromosomal aberrations in DNA aneuploid versus diploid mammary carcinomas and fibroadenomas was also found by Ried et al. [28]. Isola et al. [18] suggested a prognostic value for DNA gains on chromosomal regions $20 \mathrm{q}$ and $8 \mathrm{q}$ in exclusively node-negative tumors that were 2 to $4 \mathrm{~cm}$ in size.

In the study presented here we have investigated a small cohort of patients with invasive breast carcinomas (15 node-negative, 24 node-positive), selected on the basis of a long-term follow-up period (mean 99, range 14 to193 months) as well as available image cytometrical data. The chromosomal imbalances identified by $\mathrm{CGH}$ were investigated for their correlation with other well-established clinicopathological and image cytometrical factors. Univariate and multivariate correlations with metastasis-free survival of patients was performed to investigate the prognostic value of chromosomal imbalances.

\section{Material and method}

\subsection{Patients data and samples}

Investigations were performed on 39 invasive breast carcinomas, sampled at the Karolinska Hospital/ Sweden from 1983 to 1987 . Tumors were classified into ductal invasive (NOS, $n=34)$, lobular $(n=1)$, papillary $(n=1)$, medullary $(n=2)$, and tubular $(n=1)$ carcinomas [38]. Histological grading was performed according to Bloom and Richardson [10], modified by Elston and Ellis [13]. Immunohis- tochemical determined steroid receptor expression revealed receptor positivity for estrogen in 28 tumors, for progesterone in 21 tumors (Table 1). The patients were treated by radical mastectomy, modified radical mastectomy, or quadrantectomy. All patients investigated here participated in a therapy trial without adjuvant systemic therapy [29]. Only patients with lymph node metastases received subsequent irradiation, including the chest wall and the regional lymph nodes. All tumors were resected without residual tumor and without distant metastases at the time of operation $\left(\mathrm{R}_{0} / \mathrm{M}_{0}\right.$ category according to UICC) [34].

The mean age at the time of operation was 62 years $(\mathrm{SD} \pm 13.6)$. Patients aged 55 or younger were considered to be pre-menopausal ( $n=14)$, and patients older than 55 as post-menopausal $(n=25)$. The mean follow-up was 99 months ( \pm 56 , max. 193 months). Within the whole period of follow-up distant metastases occurred in 17 patients $(=44 \%)$.

From all tumors image cytometric data were available, which have already been proven in former studies to be of prognostic value as for example DNA histogram parameters $[3,14]$ and variation in nuclei size (anisokaryosis) [2,3]. Eleven tumors showed a diploid DNA distribution, 28 were non-diploid. Cell proliferation was indicated by determining the number of cells exceeding $2.5 \mathrm{c}$ (2.cER) and 5c (5cER), respectively.

Histopathological data of patients, immunohistochemical and image cytometric parameters, as well as, follow-up data are summarized in Table 1.

\subsection{Tissue microdissection}

Ten to 20 five $\mu \mathrm{m}$ thick sections were cut from formalin-fixed, paraffin-embedded tissue blocks. The first and the last section was stained with $H \& E$ and used for histological classification. The other sections were used for tissue microdissection in order to isolate invasive tumor cells. Further sections were used for immunohistochemical staining.

\subsection{Comparative genomic hybridization ( $\mathrm{CGH})$}

DNA was isolated from Proteinase digested (100 $\mathrm{mM}$ Tris/ $\mathrm{HCl}, 10 \mathrm{mg} / \mathrm{ml}$ proteinase $\mathrm{K}$ ) microdissected tissue according to standard protocols and labelled with biotin-16-dUTP (Boehringer Mannheim, Germany) using nick translation. $\mathrm{CGH}$ was performed according to published protocols [6,39]. Briefly, $200 \mathrm{ng}$ of tumor DNA and $200 \mathrm{ng}$ SpectrumRed-labelled normal female reference DNA (Vysis, Downers Grove, 
Table 1

Histopathological characteristics, immunohistochemical and cytometrical parameters as well as follow-up data of the 39 breast cancer patients

\begin{tabular}{|c|c|c|c|c|c|c|c|c|c|c|}
\hline Case number & Histopathology & ES-R & Pr-R & $\begin{array}{c}\text { Cyclin } \\
\text { D1 }\end{array}$ & $\begin{array}{c}\text { Follow-up } \\
\text { period } \\
\text { [months] }\end{array}$ & $\begin{array}{c}\text { Occurrence of } \\
\text { local recidive } \\
\text { [months] }\end{array}$ & $\begin{array}{c}\text { Occurrence of } \\
\text { distant } \\
\text { metastases } \\
\text { [months] }\end{array}$ & Status & $\begin{array}{c}\text { Histogram } \\
\text { type }\end{array}$ & $\begin{array}{c}\text { Value of } \\
\text { anisokaryosis } \\
\text { [pixels] }\end{array}$ \\
\hline 1 & IDC, pN0pT1, G2 & 9 & 3 & 1 & 193 & 0 & 0 & 0 & 1 & 2.6 \\
\hline 2 & IDC, $\mathrm{pN} 2 \mathrm{pT} 2, \mathrm{G} 3$ & - & - & - & 14 & 0 & 14 & 1 & 4 & 4.1 \\
\hline 3 & IDC, pN0pT2, G2 & 9 & 9 & 0 & 156 & 0 & 156 & 1 & 2 & 2.8 \\
\hline 4 & IDC, $\mathrm{pN} 2 \mathrm{pT} 2, \mathrm{G} 2$ & 0 & 0 & - & 18 & 0 & 0 & 0 & 4 & 5.2 \\
\hline 5 & IDC, $\mathrm{pN} 2 \mathrm{pT} 1, \mathrm{G} 3$ & - & - & - & 45 & 0 & 4 & 1 & 2 & 3.4 \\
\hline 6 & IDC, $\mathrm{pN} 2 \mathrm{pT} 2, \mathrm{G} 2$ & 12 & 2 & 1 & 39 & 0 & 31 & 1 & 4 & 4.7 \\
\hline 7 & IDC, $\mathrm{pN} 2 \mathrm{pT} 2, \mathrm{G} 2$ & 4 & 0 & 1 & 82 & 0 & 32 & 1 & 4 & 5.0 \\
\hline 8 & inv.tub., pN1pT, G1 & 9 & 9 & 1 & 133 & 0 & 120 & 1 & 4 & 4.1 \\
\hline 9 & IDC, pN0pT2, G2 & 12 & 6 & 0 & 94 & 0 & 0 & 0 & 1 & 2.7 \\
\hline 10 & inv.med., pN0pT1, G3 & 0 & 0 & 1 & 179 & 0 & 0 & 0 & 4 & 3.7 \\
\hline 11 & IDC, pN2pT2, G3 & - & - & 1 & 45 & 35 & 41 & 1 & 4 & 5.5 \\
\hline 12 & inv.lob., pN0pT2, G2 & 4 & 0 & 0 & 82 & 0 & 0 & 0 & 1 & 3.2 \\
\hline 13 & IDC, pN2pT2, G3 & 12 & 9 & 1 & 179 & 0 & 0 & 0 & 1 & 3.1 \\
\hline 14 & IDC, pN0pT1, G2 & - & - & 0 & 58 & 0 & 51 & 1 & 4 & 4.1 \\
\hline 15 & IDC, pN1pT2, G3 & - & - & - & 53 & 11 & 42 & 1 & 4 & 3.8 \\
\hline 16 & IDC, pN0pT2, G2 & 6 & 6 & 1 & 82 & 0 & 0 & 0 & 1 & 3.8 \\
\hline 17 & IDC, $\mathrm{pN} 2 \mathrm{pT} 1, \mathrm{G} 3$ & 2 & 0 & 2 & 37 & 23 & 23 & 1 & 3 & 4.1 \\
\hline 18 & inv.pap., pN1pT2, G2 & 9 & 4 & 3 & 118 & 0 & 49 & 0 & 4 & 4.2 \\
\hline 19 & IDC, pN1pT2, G3 & 12 & 6 & 3 & 171 & 0 & 0 & 0 & 4 & 4.1 \\
\hline 20 & IDC, $\mathrm{pN} 2 \mathrm{pT} 2, \mathrm{G} 3$ & 9 & 9 & 1 & 47 & 14 & 14 & 1 & 4 & 5.4 \\
\hline 21 & IDC, pN1pT1, G2 & 12 & 9 & 1 & 151 & 0 & 151 & 1 & 2 & 2.8 \\
\hline 22 & IDC, pN1pT2, G3 & 0 & 0 & 0 & 69 & 0 & 0 & 0 & 4 & 6.0 \\
\hline 23 & IDC, pN1pT2, G3 & 12 & 6 & 3 & 69 & 0 & 0 & 0 & 2 & 3.1 \\
\hline 24 & IDC, pN1pT2, G3 & 12 & 9 & - & 116 & 0 & 0 & 0 & 2 & 4.3 \\
\hline 25 & IDC, pN0pT1, G3 & 12 & 3 & 1 & 94 & 63 & 64 & 0 & 1 & 2.3 \\
\hline 26 & IDC, $\mathrm{pN} 2 \mathrm{pT} 2, \mathrm{G} 2$ & 6 & 0 & 0 & 185 & 0 & 0 & 0 & 4 & 3.8 \\
\hline 27 & IDC, $\mathrm{pN} 2 \mathrm{pT} 2, \mathrm{G} 3$ & 6 & 9 & 1 & 83 & 37 & 0 & 0 & 1 & 3.3 \\
\hline 28 & IDC, pN0pT2, G3 & 0 & 0 & 0 & 32 & 0 & 20 & 1 & 2 & 4.1 \\
\hline 29 & IDC, pN0pT1, G3 & 12 & 6 & 0 & 184 & 0 & 0 & 0 & 1 & 2.8 \\
\hline 30 & IDC, pN0pT1, G2 & 9 & 2 & 2 & 173 & 0 & 0 & 0 & 1 & 2.7 \\
\hline 31 & IDC, pN0pT1, G2 & 6 & 0 & 2 & 76 & 0 & 0 & 0 & 4 & 3.7 \\
\hline 32 & IDC, $\mathrm{pN} 2 \mathrm{pT} 2, \mathrm{G} 3$ & 6 & 9 & 2 & 110 & 0 & 72 & 1 & 3 & 3.8 \\
\hline 33 & IDC, pN1pT1, G3 & 12 & 3 & 2 & 27 & 0 & 0 & 0 & 1 & 2.9 \\
\hline 34 & IDC, $p N 2 p T 2, G 2$ & 6 & 3 & 1 & 183 & 0 & 0 & 0 & 4 & 3.8 \\
\hline 35 & IDC, pN0pT1, G3 & - & - & - & 161 & 0 & 0 & 0 & 3 & 4.1 \\
\hline 36 & IDC, $\mathrm{pN} 2 \mathrm{pT} 2, \mathrm{G} 3$ & 12 & 0 & 1 & 45 & 0 & 29 & 1 & 4 & 4.8 \\
\hline 37 & IDC, pN0pT2, G2 & 9 & 0 & - & 146 & 0 & 0 & 0 & 3 & 2.8 \\
\hline 38 & IDC, pN1pT2, G2 & 9 & 9 & - & 71 & 0 & 0 & 0 & 1 & 2.4 \\
\hline 39 & inv.med, pN0pT2, G3 & 0 & 0 & - & 68 & 0 & 0 & 0 & 4 & 5.8 \\
\hline
\end{tabular}

IDC = invasive ductal carcinoma, NOS; inv.tub/ inv.med./ inv.pap./ inv.lob. = invasive tubulary, medullary, papillary and lobulary carcinoma; ES-R, Pr-R = estrogene and progesteron receptor status, scored negative, or $3+, 6+, 9+$, or $12+$;

Cyclin D1 immunohistochemistry, scored negative, or $1+, 2+$, or $3+$; '-' $=$ no data available;

Histogram types according to Auer et al. [8]: $1=$ diploid stemline, $2=$ diploid and/or tetraploid stemline, $3=$ diploid proliferative, $4=$ irregularly distribution with cells over $4 \mathrm{c}$;

Anisokaryosis = variation in nuclei size [pixels], determined by image cytometry. 
IL) were hybridized together with $40 \mu \mathrm{g}$ Cot-1 DNA (Life Technologies, Grand Island, NY) onto normal metaphase spreads. Tumor DNA was detected by Cy2conjugated streptavidin and biotinylated anti-streptavidin conjugates (Amersham Buchler, Braunschweig, Germany).

Image acquisition and processing was performed as described previously [6,39], using a digital image analysis system (MetaSystems, Altlusheim, Germany). Green to red (tumor to normal) fluorescence ratio profiles were calculated for each chromosome to determine copy number changes in the tumors [6,20,21,39]. Profiles were compared either using fixed red/green ratio thresholds ( 0.8 and 1.25 ), or with calculated confidence limits that have been determined by the analysis software using $t$-statistics and a specified error probability ( \pm 3 times SD). If the measured ratio was outside of the intervals in both procedures, a gain or loss in the tumor DNA was assumed. Non-tumorous tissues were microdissected from the paraffin sections and processed identically to verify the reliability of our $\mathrm{CGH}$ protocol. All non-tumorous tissue samples resulted in CGH profiles with ratios within the described conditions.

\subsection{Statistical analysis}

Statistical analyses were performed using SAS software (SAS Inst., Cary, NC, USA). Fisher's exact test was used to identify differences in frequencies of chromosomal aberrations between metastasizing and non-metastasising tumors, between node-negative and node-positive patients, and between patients grouped according to their DNA-histogram, morphometrical and immunohistochemical parameters. Significance was determined by the Fisher's exact test.

Kaplan-Meier survival curves were calculated to determine a potential correlation of individual variables with metastasis-free survival of patients. For this purpose continuous variables (anisokaryosis, exceeding rates) were grouped according to quantification models. The significance of overall differences between survival curves was determined with the log-rank test.

Multivariate analyses were performed with the Cox proportional hazards model. Due to the low overall frequency of metastasis events $(n=17)$, no more than two variables were included into the model. Thus, each univariate significant parameter was fitted together with nodal status in a bivariate model. Significance of parameters was derived using the Wald $\chi^{2}$-test.
In all statistical analyses significance was assumed for $p \leqslant 0.05$. The occurrence of distant metastasis was considered as the prognostic criteria.

\section{Results}

\subsection{Chromosomal alterations and their association with other variables}

A summary of $\mathrm{CGH}$ results is given in Fig. 1. The mean number of chromosomal alterations per tumor was $6.5 \pm 0.7$ (range 2 to 18 ). The most frequent chromosomal imbalances, present in more than $33 \%$ of the cases, were gains on 11q13,12q24, 16, 17, 20q, and losses on $2 \mathrm{q}$ and $13 \mathrm{q}$.

Comparison of chromosomal imbalances in patients with or without occurrence of distant metastases during the follow-up period identified significantly different frequencies for gains on chromosome 11q13 and $12 \mathrm{q} 24$ ( $p=0.01$ and 0.006 , respectively), and for loss on $12 q(p=0.02)$. All of these alterations were more frequent in patients without distant metastasis. From the 22 metastasis-free cases, gain on $11 \mathrm{q} 13$ was identified in 12 tumors, gain on $12 \mathrm{q} 24$ in 13 tumors, and loss on $12 q$ in 6 tumors.

No significant differences in the frequency of chromosomal aberrations were found between node positive and negative tumors, between grade $1 / 2$ and grade 3 tumors, or between tumors sized pT1 and pT2 $(p>$ $0.05)$. Furthermore, tumors grouped according to proliferation using the $2.5 \mathrm{c}$ or $5 \mathrm{c}$ exceeding rate, or according to their anisokaryosis value, did not show differences in chromosomal alterations. Gain on chromosome 17 , however, was detected more frequently in non-diploid $(16 / 28)$ than in diploid tumors $(2 / 11)$ $(p=0.04)$.

\subsection{Univariate prognostic value of parameters}

Four chromosomal imbalances showed a significant univariate prognostic value for the metastasis-free survival of patients $(p \leqslant 0.05)$ : gains on chromosome 11q13, 12q24, 17, and 18p (Table 2). No univariate prognostic significance was found for the gain on chromosome 20q. Kaplan-Meier survival curves for the most important chromosomal alterations are plotted in Fig. 2.

Patients grouped according to the proliferation parameter $(2.5 \mathrm{c}$ or $5 \mathrm{c}$ exceeding rates) did not show different clinical courses. However, 10/11 patients with 

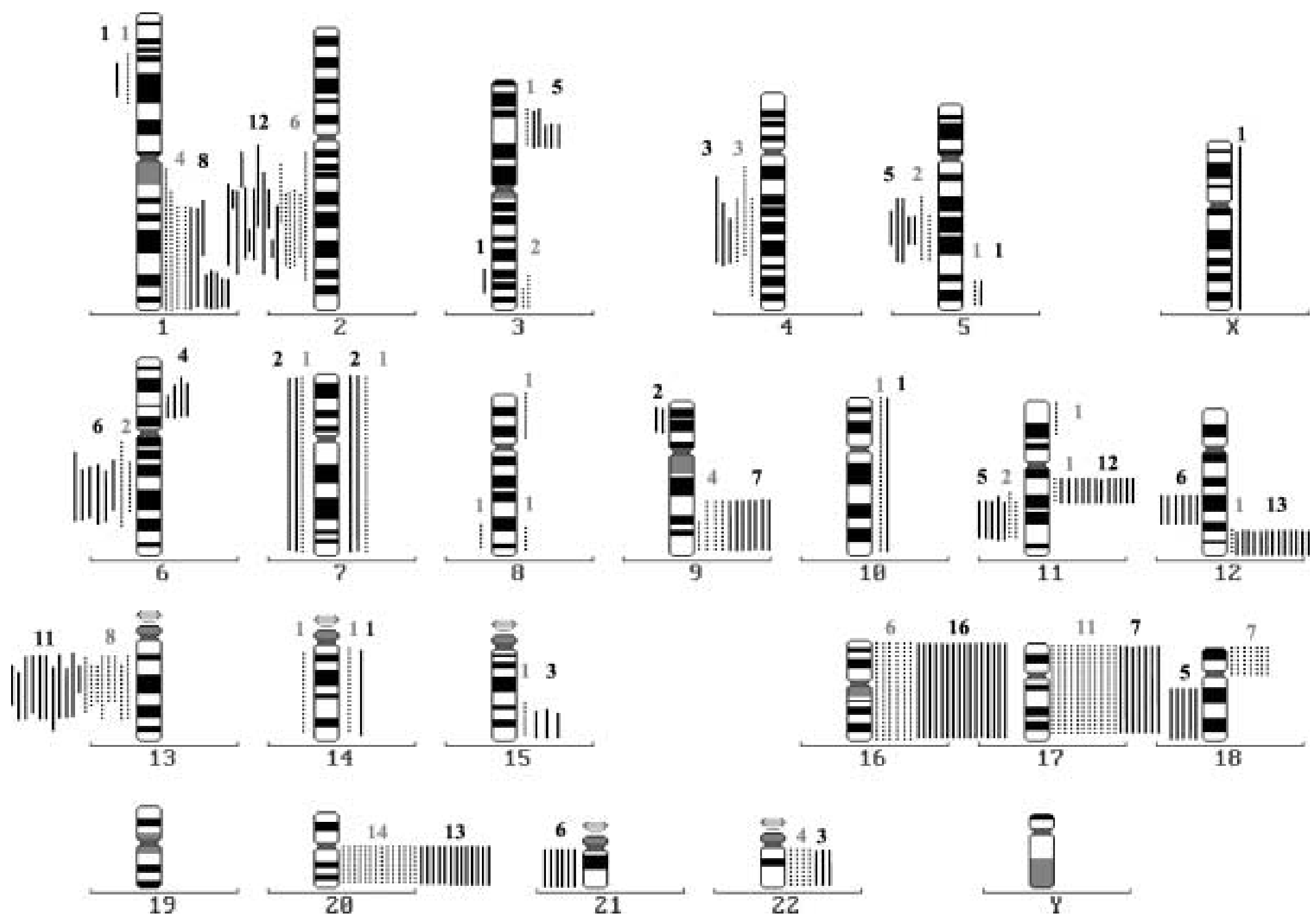

Fig. 1. Ideogram presenting the CGH results from 39 invasive breast carcinomas. Gains are indicated on the right, losses on the left side of the corresponding chromosome. Those alterations identified in tumors building distant metastases during follow-up are plotted in dotted lines, those which are not in solid lines. Additionally the number of cases showing an alteration is given. 
Table 2

Results from Kaplan-Meier analyses with the number of patients per group, the number of metastasesfree patients and the significance values

\begin{tabular}{|c|c|c|c|c|c|}
\hline Parameter & Groups & No. of patients & $\begin{array}{l}\text { Metastases- } \\
\text { free patients }\end{array}$ & {$[\%]$} & $\begin{array}{c}\text { log-rank } \\
p \text {-value }\end{array}$ \\
\hline \multirow[t]{3}{*}{ pos. LN } & 0 & 15 & 11 & $73 \%$ & \\
\hline & $1-3$ & 17 & 10 & $59 \%$ & \\
\hline & $>3$ & 7 & 1 & $14 \%$ & 0.001 \\
\hline \multirow[t]{2}{*}{ DNA-ploidy } & diploid & 11 & 10 & $91 \%$ & \\
\hline & non-diploid & 28 & 12 & $43 \%$ & 0.01 \\
\hline \multirow[t]{2}{*}{ Anisok. } & $<3.85$ & 22 & 16 & $82 \%$ & \\
\hline & $\geqslant 4$ & 17 & 6 & $41 \%$ & 0.003 \\
\hline \multirow[t]{2}{*}{$11 q 13+$} & no & 26 & 10 & $38 \%$ & \\
\hline & yes & 13 & 12 & $92 \%$ & 0.002 \\
\hline \multirow[t]{2}{*}{$12 q 24+$} & no & 25 & 9 & $36 \%$ & \\
\hline & yes & 14 & 13 & $93 \%$ & 0.0003 \\
\hline \multirow[t]{2}{*}{$17+$} & no & 21 & 15 & $71 \%$ & \\
\hline & yes & 18 & 7 & $39 \%$ & 0.05 \\
\hline \multirow[t]{2}{*}{$18 \mathrm{p}+$} & no & 32 & 22 & $69 \%$ & \\
\hline & yes & 7 & 0 & $0 \%$ & 0.0003 \\
\hline \multirow[t]{2}{*}{$20 q+$} & no & 12 & 9 & $75 \%$ & \\
\hline & yes & 27 & 13 & $48 \%$ & 0.13 n.s. \\
\hline
\end{tabular}

pos. $\mathrm{LN}=$ number of positive axillary lymph nodes;

DNA-ploidy = visual classification of DNA-histograms in diploid and non-diploid [8];

Anisok. = anisokaryosis, cytometrical determined variation of nuclei size [pixels];

Chromosomal gains (+), losses (-) from CGH analyses.

diploid tumor-DNA distribution remained free of distant metastases, whereas those with non-diploid tumors showed a metastases-free survival rate of only $43 \%$ ( $p=0.01)$. Significant differences in the metastases-free survival were also found for patients with low $(<3.8$ pixels $)$ and high $(\geqslant 4.0)$ anisokaryosis values ( $p=0.003)$ (Table 2, Fig. 2).

Using Kaplan-Meier analysis no significant influence of histological type, tumor size and grading, steroid hormone receptor status, cyclin D1, or menopausal status on the clinical outcome was found. Among the histopathological parameters, the nodal status, as expected was the only one showing strong prognostic value for a metastasis-free survival of patients $(p=0.001)$ (Table 2, Fig. 2).

\subsection{Independent prognostic value of parameters}

Each of the parameters showing significance in univariate analyses was fitted together with the nodal status in a bivariate model using Cox proportional hazards analyses. In Table 3 the results are listed with significance values of the pairwise tested parameters. Independent prognostic value was identified for anisokaryosis, DNA-ploidy, and the DNA gains on $11 \mathrm{q} 13,12 \mathrm{q} 24,17$ and 18p. Gain on 20q, which was not significant in an univariate analysis, was also investigated and showed a weak predictive value in combination with the lymph node status ( $p=0.03$ ).

To prove a possible interaction between single imbalances, or their inter-dependence chi $^{2}$-test was performed. A positive correlation was found between gains on $11 \mathrm{q} 13$ and $12 \mathrm{q} 24$ ( $p=0.004)$, both alterations showed an inverse correlation with gain on $18 \mathrm{p}$ ( $p=0.04$ and $p=0.03$, respectively). No correlation was found between $11 \mathrm{q} 13$ and $12 \mathrm{q} 24$, and gains on chromosomes 17 or $20 \mathrm{q}$.

\subsection{Discussion}

In breast carcinomas many other parameters besides the histopathological parameters have been included in prognostic studies. These include amplification of oncogenes such as HER2/neu, MYC, or cyclin D1, and mutation of several tumor suppressor genes such as p53 (for a review see [9]). Additional prognostic parameters include those derived from image cytometrical measurements such as DNA histogram type [4,8,14], 


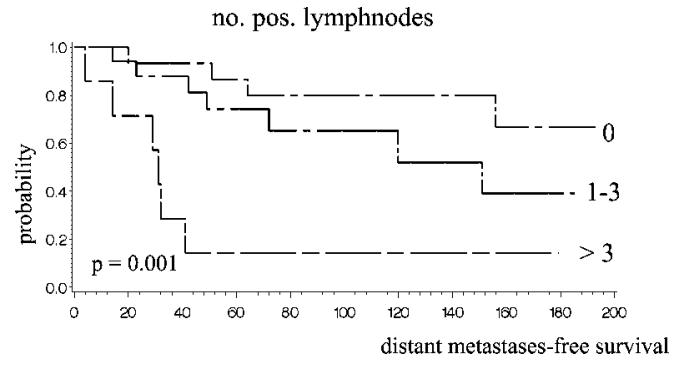

(a)

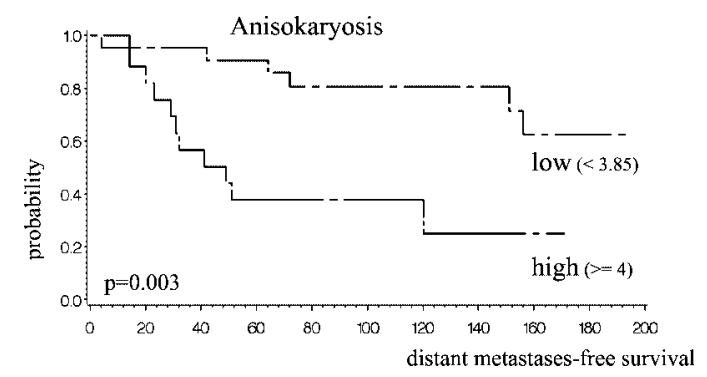

(c)

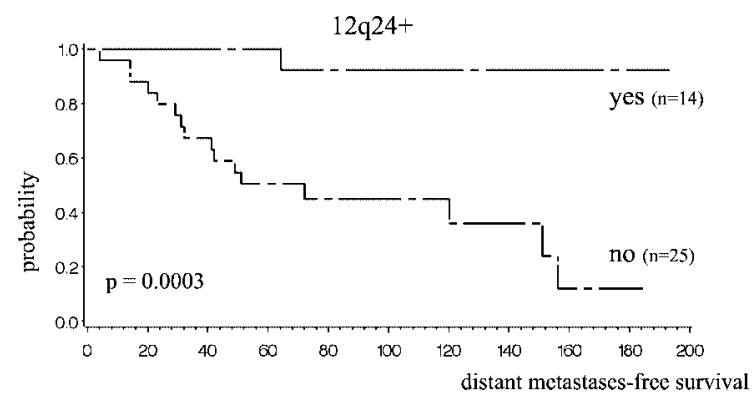

(e)

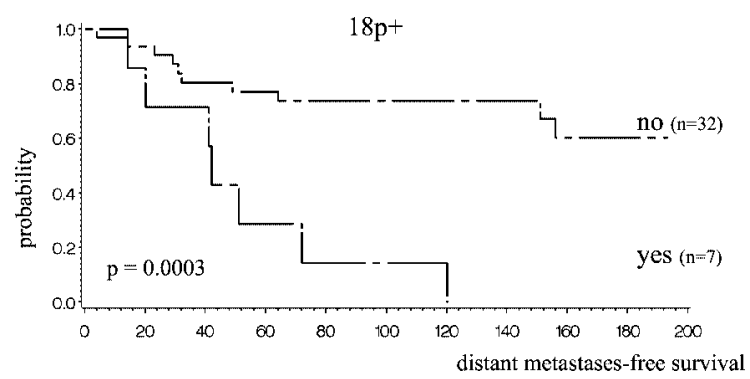

(g)

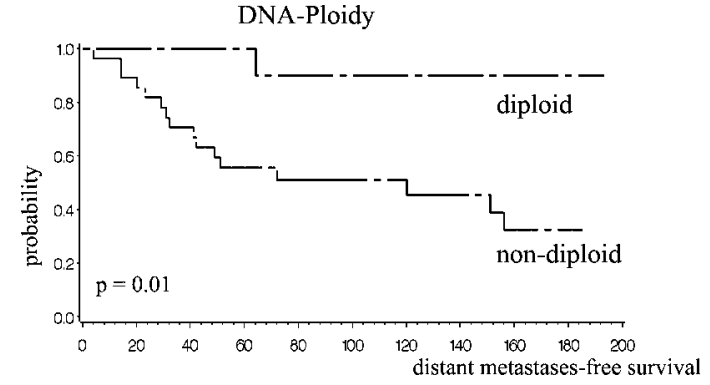

(b)

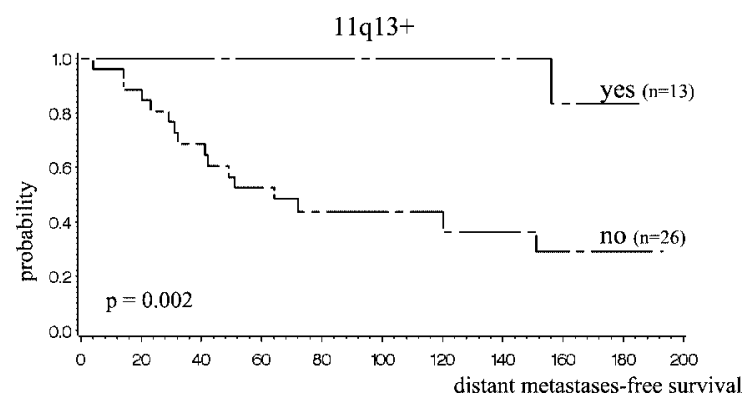

(d)

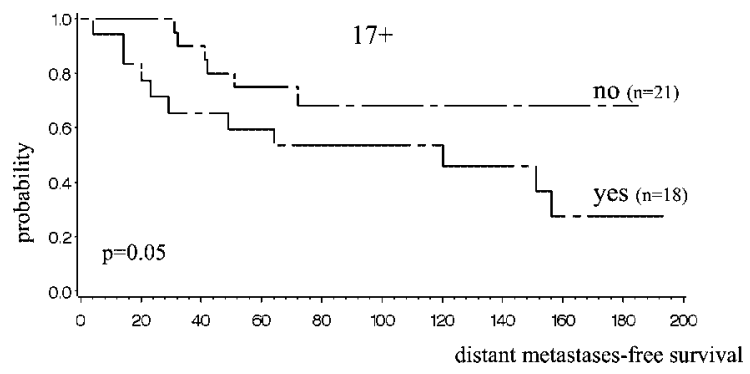

(f)

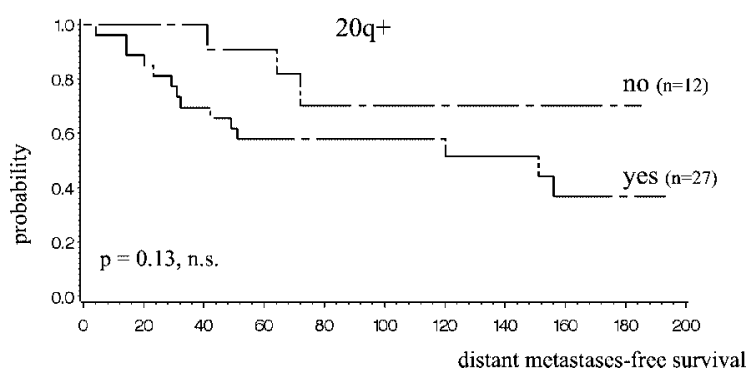

(h)

Fig. 2. Kaplan-Meier curves for a metastases-free survival of patients stratified according to the number of positive lymph nodes, DNA ploidy, anisokaryosis, and the chromosomal alterations on 11q13,12q24, 17, 18p, and 20q. Gain on 20q, which was not significant in univariate analysis, is demonstrated because of it's suggested prognostic value in other studies [10]. 
Table 3

Results from Cox Proportional Hazard analyses. Each univariate significant parameter was investigated bivariate with the lymph node status. Given are p-valus for the first and second parameter, respectively, and the risk factors

\begin{tabular}{lcccc}
\hline $\begin{array}{c}\text { 1st parameter } \mathrm{pN} \\
p\left(\text { Wald }^{2}\right)\end{array}$ & Risk factor & 2 nd parameter & $p$ (Wald $\left.{ }^{2}\right)$ & Risk factor \\
\hline 0.004 & 3.4 & $11 \mathrm{q}+$ & 0.01 & 0.07 \\
0.002 & 3.8 & $12 \mathrm{q}+$ & 0.004 & 0.04 \\
0.002 & 3.7 & $17+$ & 0.02 & 3.4 \\
0.01 & 2.6 & $18 \mathrm{p}+$ & 0.007 & 4.2 \\
0.0009 & 3.9 & $20 \mathrm{q}+$ & 0.03 & 4.3 \\
0.01 & 2.6 & anisokaryosis & & 3.3 \\
0.006 & $(<3.9 />4.0)$ & 0.03 & \\
\hline
\end{tabular}

S-phase fraction of tumor cells [24], and morphometric parameters [2,3]. There is, however, an urgent need for more accurate prognostic indicators for use in therapy selection according to the individual risk of patients of developing metastatic disease.

The comparative genomic hybridization $(\mathrm{CGH})$ technique has been shown to be a powerful method for screening tumour tissues for evidence of chromosomal gains and losses. In breast cancer several studies have identified chromosomal imbalances, with the most frequent gains affecting chromosomes 1q, 6p, 8q, 11q13, 17, and 20q. Losses, which are less frequent have been found on $6 \mathrm{q}, 12 \mathrm{q} 24$, and 13q [6,18,20,23,27,28,33,36]. In general the pattern of gains and losses identified in these studies is in agreement with our current findings.

Few authors have investigated the association between chromosomal alterations and clinico-pathological, immunohistochemical or image cytometrical data and clinical outcome [17,18]. Hermsen et al. [17] used frozen tissue from lymph node-negative breast carcinomas and compared CGH results with pathological data and cytometrical measurements. They could show that aneuploid tumors harboured more gains and losses than diploid ones. CGH results from fresh-frozen tissue samples have also been reported by Isola et al. [18] and Jain et al. [19]. Recently Jain et al. have described a statistical method to identify correlations between large-scale multivariate measurements and clinical outcome. The authors used this method to identify loci $(8 \mathrm{q} 24+$ and $9 q 13+)$ correlating with poor survival. In the study of Isola et al. selectively advanced (pT2) node negative cases were investigated with a median follow-up of 5 years. The most frequently identified aberrations here are largely in agreement with our findings. They found losses to be significantly higher in cases with early recurrence, but none of the losses could be associated with clinical outcome. A significant association with recurrence, however, was established for high level amplification on chromosome 8q, which harbours the MYC oncogene. The latter feature was only rarely seen in our cases.

A striking prognostic correlation was found by Isola et al. [18] for amplification on 20q, which they identified in 7 cases, 6 of which had early recurrence in less than 32 months. In our study $20 q+$ was identified in 27/39 patients, but univariate correlation with metastases-free survival was not significant. Also when performing separate analyses for node-negative and positive cases (data not shown here) no significance could be identified for a correlation between $20 \mathrm{q}+$ and outcome. In bivariate analysis combined with nodal status the $20 \mathrm{q}+$ alteration shows significance, however with a $p$-value below that of the other aberrations (see Table 3 ).

Increased copy number at $20 \mathrm{q} 13$ has emerged as one of the most common genetic aberrations in invasive breast carcinomas $[6,18,20,31]$. Three independently amplified regions on 20q13.2 [31,32] harbouring several genes including a nonreceptor tyrosinephosphatase gene (PTPN1), as well as AIB3 and AIB4 have been implicated [16,32]. The amplifications of this region were described as characteristic of advanced breast cancer in each of these studies, though they were not found in in situ lesions investigated by Kuukasjärvi et al. [23]. In our studies this alteration was frequently identified in invasive and in situ breast carcinomas and, furthermore, in ductal hyperplasias adjacent to invasive carcinoma [5,7,37]. Consequently, we suggest that gain on 20q may play an important role in tumor development itself, rather than favoring the development of metastasis. 
In the present study the prognostic value of chromosomal imbalances was investigated on 39 invasive breast carcinomas. Although the number of cases is low, the prognostic significance of some imbalances was impressive. We noted no difference in the distribution of chromosomal alterations between node positive and negative tumors. However, marked differences between diploid and non-diploid tumors (gain on 17) and, most interestingly, between tumors developing distant metastases and those which did not (gains on 11q13, $12 q 24$, loss on 12q). Furthermore, we found a striking univariate correlation with clinical outcome of patients for nodal status, DNA-ploidy, anisokaryosis, and for gains on 11q13, 12q24, 17 and 18p.

Amplification on chromosome 17 is commonly found in invasive breast cancer [5-7]. The chromosomal region $17 \mathrm{q}$, including the HER2/neu locus, was also identified in invasive carcinomas $[6,23,27,33]$ and in premalignant lesions [5,7]. Ried et al. [28] observed this alteration more frequently in aneuploid rather than in diploid tumors, which is in accordance with our results here. Furthermore we found a significant univariate and bivariate correlation between gain on 17 and the metastases-free survival of patients.

The chromosomal alterations with the most striking association with clinical outcome were gains on $11 \mathrm{q} 13,12 \mathrm{q} 24$, and 18p. Gain on chromosomal region $11 \mathrm{q} 13$ has been reported by others, albeit with variable frequencies $[17,18,25,28,30]$. A clustering of several genes within this chromosomal region was described [22], including the cyclin D1 oncogene (PRAD1/CCND1), the proto-oncogenes EMS1 (human v-src homologue), INT2/FGF3 (fibroblast growth factor3) and GSTP1 (gluthathione S transferase). The cyclin D1 gene has been shown to be amplified in a proportion of breast carcinomas [22,35], and controls cellular proliferation by regulating the G1/S cell cycle checkpoint. We show 13/39 cases of invasive breast carcinomas with gain on 11q13. An unexpected inverse, but highly significant, correlation with the clinical outcome of these patients was found. No significant association between gain on 11q13 and cyclin D1 positive immunohistochemistry could be found (data not shown). Thus, either amplification of the cyclin D1 oncogene is present but does not correspond to its expression level, or the identified gain on 11q13 must result in the amplification of genes other than cyclin D1.

An inverse correlation with clinical outcome of patients was also found for gain on chromosomal region $12 \mathrm{q} 24$. For this region no candidate genes responsible for the amplification have been described (http://www.ncbi.nlm.gov).
DNA gain on chromosome $18 \mathrm{p}$ was inversely correlated with gains on $11 \mathrm{q} 13$ and $12 \mathrm{q} 24$, but positively correlated with clinical outcome. Only 7 cases showed gain on 18p, however, all developed metastases within the follow-up period. Although this result is highly significant, in view of the small number of cases it should be interpreted cautiously.

An independent prognostic value was identified for chromosomal gains on 11q13, 12q24, 17, and 18p, and, in combination with nodal status, also for gain on 20q. An unexpected inverse correlation of two chromosomal alterations with clinical outcome was found. On the basis of the currently available data this cannot be explained. However, assuming, that more than one genetic alteration may be involved in the metastatic processes interactions between amplified genes in several chromosomal regions is imaginable. In a previous study of genetic alterations in breast carcinomas, amplifications of several genes were associated with clinical outcome [12]. The strong association identified for gains on 11q13 and 12q24 (positive correlation), as well as the inverse correlation of both with alterations on $18 p$ but not with alterations on 17 and $20 q$ we observed here, may also be caused by such genetic interactions.

For the first time chromosomal alterations in formalin-fixed, paraffin-embedded breast carcinoma tissues were correlated with image cytometrical and immunohistochemical parameters as well as with distant metastasis events during a long follow-up period. Although the number of patients is small the results clearly demonstrate a striking prognostic significance of chromosomal alterations independent of nodal status. The latter, and the interaction and/or dependence of specific chromosomal alterations on each other, must be the basis for further studies.

\section{Acknowledgement}

We gratefully acknowledge the excellent technical assistance of Daniela Angermaier and Ilse Di Grazia. This work was supported by Wilhelm Sander-Stiftung, München, Germany, contract number 9607 01/2.

\section{References}

[1] M. Aubele, G. Auer, U. Falkmer, A. Voss, K. Rodenacker, U. Jütting and H. Höfler, Identification of a low-risk group of stage I-breast cancer patients by cytometrically assessed DNA and nuclei texture parameters, J. Pathol. 177 (1995), 377-384. 
[2] M. Aubele, G. Auer, U. Falkmer, A. Voss, K. Rodenacker, L.E. Rutquist and H. Höfler, Improved prognostication in small (pT1) breast cancers by image cytometry, Breast Cancer Res. Treat. 36 (1995), 83-91.

[3] M. Aubele, G. Auer, A. Voss, U. Falkmer, L.E. Rutquist and H. Höflerand, Different risk groups in node-negative breast cancer: Prognostic value of cytophotometrical assessed DNA, morphometry and texture, Int. J. Cancer 63 (1995), 7-12.

[4] M. Aubele, G. Auer, A. Voss, U. Falkmer, L.E. Rutquist and H. Höfler, Disease-free survival of node-positive breast cancer patients: improved prognostication by cytometrical parameters, Path. Res. Pract. 191 (1995), 982-990.

[5] M. Aubele, M. Cummings, A. Mattis, H. Zitzelsberger, A. Walch, M. Kremer, H. Höfler and M. Werner, Accumulation of chromosomal imbalances from intraductal proliferative lesions to adjacent in situ and invasive ductal breast cancer, $D i$ agnostic Molec. Pathol. 9(1) (2000), 14-19.

[6] M. Aubele, A. Mattis, H. Zitzelsberger, A. Walch, M. Kremer, P. Hutzler, H. Höfler and M. Werner, Intratumoral heterogeneity in breast carcinoma revealed by laser-microdissection and comparative genomic hybridization, Cancer Genet. Cytogenet. 110 (1999), 94-102.

[7] M. Aubele, A. Mattis, H. Zitzelsberger, A. Walch, M. Kremer, G. Welzl, H. Höfler and M. Werner, Extensive ductal carcinoma in situ with small foci of invasive ductal carcinoma: Evidence of genetic resemblance by CGH, Int. J. Cancer 85 (2000), 8286.

[8] G.U. Auer, T. Caspersson and A. Wallgren, DNA content and survival in mammary carcinoma, Analyt. Quant. Cytol. Histol. 3 (1980), 161-165.

[9] R. Bieche and R. Lidereau, Genetic alterations in breast cancer, Genes Chromos. Cancer 14 (1995), 227-251.

[10] H.J. Bloom and W.W. Richardson, Histological grading and prognosis in breast cancer. A study of 1049 cases of which 359 have been followed for 15 years, Br. J. Cancer 11 (1957), 359377.

[11] E.D. Coene, V. Schelfhout, R.A. Winkler, A.-M. Schelfhaut, N. van Roy, M. Grooteclaes, F. Speleman and C.R. de Potter, Amplification units and translocation at chromosome $17 \mathrm{q}$ and c-erbB-2 overexpression in the pathogenesis of breast cancer, Virchows Arch. 430 (1997), 365-372.

[12] M. Cuny, A. Kramar, F. Courjal, V. Johannsdottir, B. Iacopetta, H. Fontaine, J. Grenier, S. Culine and C. Theillet, Relating genotype and phenotype in breast cancer: an analysis of the prognostic significance of amplification at eight different genes or loci and of p53mutations, Cancer Res. 60 (2000), 10771083.

[13] C.W. Elston and J.D. Ellis, Pathological prognostic factors in breast cancer. I. The value of histological grade in breast cancer: experience from a large study with long-term follow-up, Histopathol. 19 (1991), 403-410.

[14] A.G. Fallenius, G.U. Auer and J.M. Carstensen, Prognostic significance of DNA measurements in 409 consecutive breast cancer patients, Cancer 62 (1988), 521-530.

[15] R.K. Gregory, T.J. Powles, J. Salter, J.C. Chang, S. Ashley and M. Dowsett, Prognostic relevance of cerbB2 expression following neoadjuvant chemotherapy in patients in a randomised trial of neoadjuvant versus adjuvant chemoendocrine therapy, Breast Cancer Res. Treat. 59 (2000), 171-175.
[16] X.-Y. Guan, J. Xu, S.L. Anzick, H. Zhang, J.M. Trent and P.S. Meltzer, Hybrid selection of transcribed sequences from microdissected DNA: isolation of genes within an amplified region at 20q11-20q13.2 in breast cancer, Cancer Res. 56 (1996), 3446-3450.

[17] M.A.J.A. Hermsen, J.P.A. Baak, G.A. Meijer, J.M. Weiss, J.W.W. Walboomers, P.J.F. Snijder and P.J. van Diest, Genetic analysis of 53 lymph node-negative breast carcinomas by CGH and relation to clinical, pathological, morphometric, and DNA cytometric prognostic factors, J. Pathol. 186 (1998), 356-362.

[18] J.J. Isola, O.-P. Kallioniemi, L.W. Chu, S.A.W. Fuqua, S.G. Hilsenbeck, C.K. Osborne and F.M. Waldman, Genetic aberrations detected by comparative genomic hybridization predict outcome in node-negative breast cancer, Am. J. Pathol. 147 (1995), 905-911.

[19] A.N. Jain, K. Chin, A.-L. Borresen-Dale, B.K. Erikstein, P.E. Lonning, R. Kaaresen and J.W. Gray, Quantitative analysis of chromosomal CGH in human breast tumors associates copy number abnormalities with p53 status and patient survival, PNAS 98 (2001), 7952-7957.

[20] A. Kallioniemi, O.-P. Kallioniemi, J. Piper, M. Tanner, T. Stokke, L. Chen, H,S. Smith, D. Pinkel, J.W. Gray and F.M. Waldman, Detection and mapping of amplified DNA sequences in breast cancer by comparative genomic hybridization, Proc. Natl. Acad. Sci. USA 91 (1994), 2156-2160.

[21] O.P. Kallioniemi, A. Kallioniemi, J. Piper, J. Isola, F.M. Waldman, J.W. Gray and D. Pinkel, Optimizing comparative genomic hybridization for analysis of DNA sequence copy number changes in solid tumors, Genes Chromos. Cancer 10 (1994), 231-243.

[22] J. Koreth, P.B. Bethwaite and J.O.D. McGee, Mutation at chromosome $11 \mathrm{q} 23$ in human non-familial breast cancer: a microdissection microsatellite analysis, J. Pathol. 176 (1995), 1118.

[23] T. Kuukasjärvi, R. Karhu, M. Tanner, M. Kahkonen, A. Schaffer, N. Nupponen, S. Pennanen, A. Kallioniemi, O.P. Kallioniemi and J. Isola, Genetic heterogeneity and clonal evolution underlying development of asynchronous metastasis in human breast cancer, Cancer Res. 57 (1997), 1597-1604.

[24] E. Merkel, D.J. Winchester, R.A. Goldschmidt, C.Z. August, D.M. Wruck and A.W. Rademaker, DNA flow cytometry and pathologic grading as prognostic guides in axillary lymphnode-negative breast cancer, Cancer 72 (1993), 1926-1932.

[25] E. Moore, H. Magee, J. Coyne, T. Gorey and P.A. Dervan, Widespread chromosomal abnormalities in high-grade ductal carcinoma in situ of the breast. Comparative genomic hybridization study of pure high-grade DCIS, J. Pathol. 187 (1999), 403-409.

[26] D.S. Murphy, P. McHardy, J. Coutts, E.A. Mallon, W.D. George, S.B. Kaye, R. Brown and W.N. Keith, Interphase cytogenetic analysis of erbB2 and topoII(co-amplification in invasive breast cancer and polysomy of chromosome 17 in ductal carcinoma in situ, Int. J. Cancer 64 (1995), 18-26.

[27] T. Nishizaki, S. DeVries, K. Chew, W.H. Goodson, B.M. Ljung, A. Thor and F.M. Waldman, Genetic alterations in primary breast cancers and their metastases: direct comparison using modified comparative genomic hybridization, Genes Chromos. Cancer 19 (1997), 267-272. 
[28] T. Ried, K.E. Just, H. Holtgreve-Grez, S. duManoir, M.R. Speicher, E. Schröck, C. Latham, H. Blegen, A. Zetterberg, T. Cremer and G. Auer, Comparative genomic hybridization of formalin-fixed, paraffin-embedded breast tumors revealed different patterns of chromosomal gains and losses in fibroadenomas and diploid and aneuploid carcinomas, Cancer Res. 15 (1995), 5415-5420.

[29] Stockholm Breast Cancer Study Group, Breast cancer management program for women with breast cancer in the Stockholm. Gotland region, The Oncologic Centre, Karolinska Hospital, Stockholm, 1987.

[30] M.M. Tanner, R.A. Karhu, N.N. Nupponen, A. Borg, B. Baldetorp, T. Pejovic, M. Ferno, D. Killander and J.J. Isola, Genetic aberrations in hypodiploid breast cancer: frequent loss of chromosome 4 and amplification of cyclin D1 oncogene, Am. J. Pathol. 153 (1998), 191-199.

[31] M.M. Tanner, M. Tirkkonen, A. Kallioniemi, C. Collins, T. Stokke, R. Karhu, D. Kowbel, F. Shadravan, M. Hintz, W.-L. Kuo, F.M. Waldman, J.J. Isola, J.W. Gray and O.-P. Kallioniemi, Increased copy number at $20 \mathrm{q} 13$ in breast cancer: defining the critical region and exclusion of candidate genes, Cancer Res. 54 (1994), 4257-4260.

[32] M.M. Tanner, M. Tirkkonen, A. Kallioniemi, J. Isola, T. Kuukasjärvi, C. Collins, D. Kowbel, X.-Y. Guan, J. Trent, J.W. Gray, P. Meltzer and O.-P. Kallioniemi, Independent amplification and frequent co-amplification of three nonsyntenic regions on the long arm of chromosome 20 in human breast cancer, Cancer Res. 56 (1996), 3441-3445.

[33] M. Tirkkonen, M. Tanner, R. Karhu, A. Kallioniemi, J. Isola and O.-P. Kallioniemi, Molecular cytogenetics of primary breast cancer by CGH, Genes, Chromos. Cancer 21 (1998), 177-184.
[34] UICC (International Union against Cancer), Classification of Malignant Tumors, L.H. Sobin and C. Wittekind, eds, WileyLiss, New York, 1997.

[35] R.A. Walker, L.J. Jones, S. Chappell, T. Walsh and J.A. Shaw, Molecular pathology of breast cancer and its application to clinical management, Cancer and Metastasis Reviews 16 (1997), 5-27.

[36] R.G. Weber, M. Scheer, I.A. Born, S. Joos, J.M.J.L. Cobbers, C. Hofele, G. Reifenberger, J.E. Zöller and P. Lichter, Recurrent chromosomal imbalances detected in biopsy material from oral premalignant and malignant lesions by combined tissue microdissection, universal DNA amplification, and comparative genomic hybridization, Am. J. Pathol. 153 (1998), 295303.

[37] M. Werner, A. Mattis, M. Aubele, M. Cummings, P. Hutzler and H. Höfler, 20q13.2 amplification in intraductal hyperplasia adjacent to in situ and invasive cancer of the breast, Virchows Arch. 435 (1999), 469-472.

[38] World Health Organiziation (WHO), Histological Typing of Breast Tumors, 2nd edn, International histologic classification of tumors, 2, WHO, Geneva, 1981.

[39] H. Zitzelsberger, U. Kulka, L. Lehmann, A. Walch, J. Smida, M. Aubele, T. Lörch, H. Höfler, M. Bauchinger and M. Werner, Genetic heterogeneity in a prostatic carcinoma and associated prostatic intraepithelial neoplasia as demonstrated by combined use of laser-microdissection, degenerate oligonucleotide primed PCR and comparative genomic hybridization, Virchows Arch. 433 (1998), 297-304. 


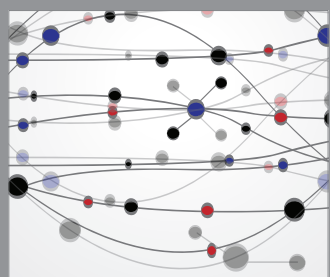

The Scientific World Journal
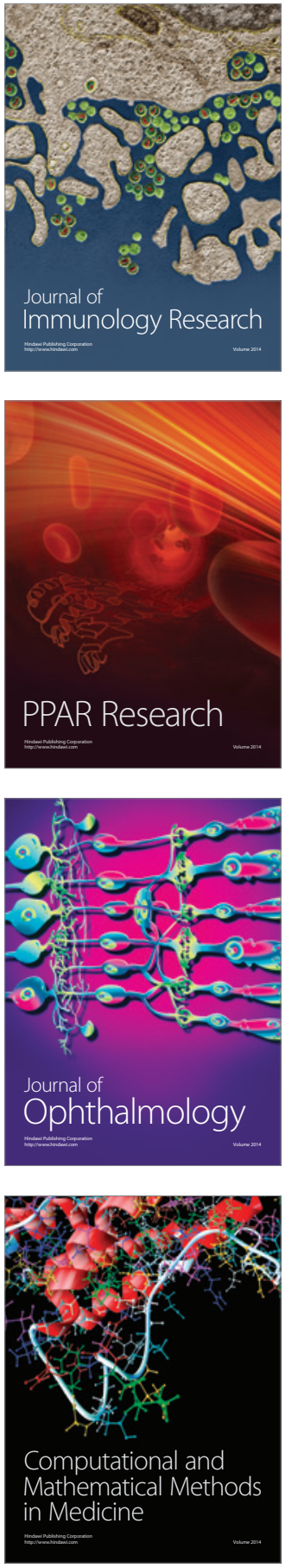

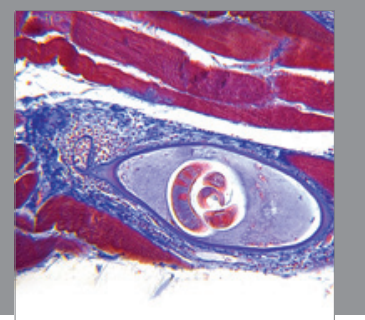

Gastroenterology

Research and Practice
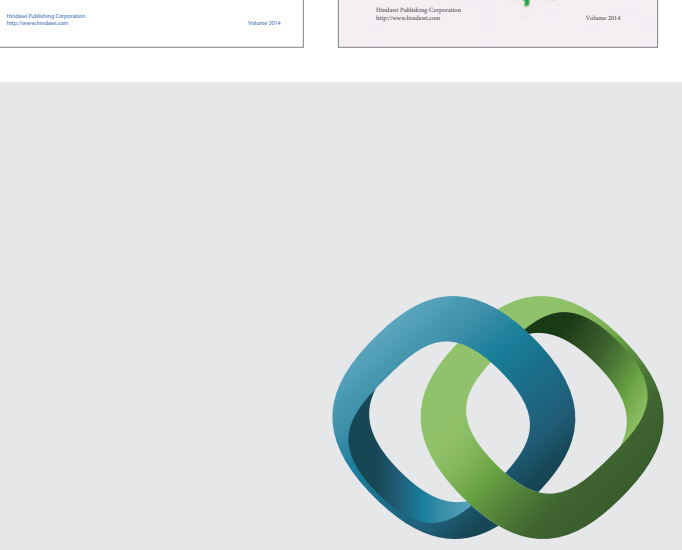

\section{Hindawi}

Submit your manuscripts at

http://www.hindawi.com
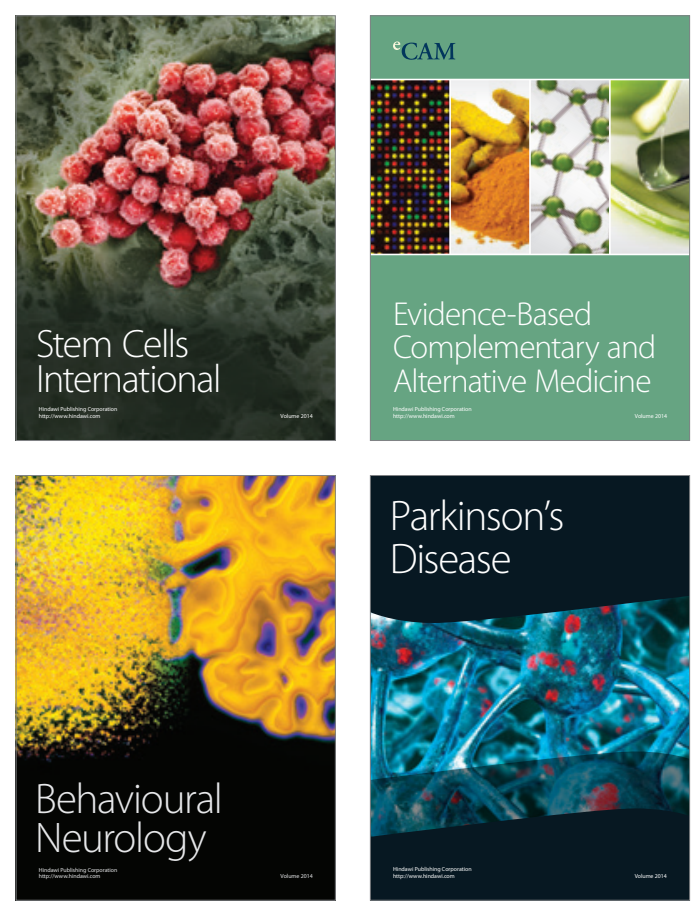

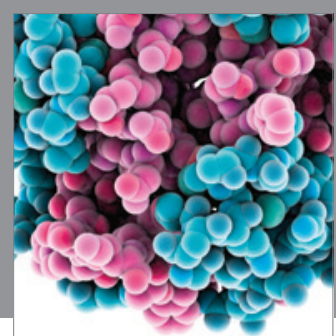

Journal of
Diabetes Research

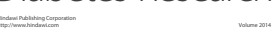

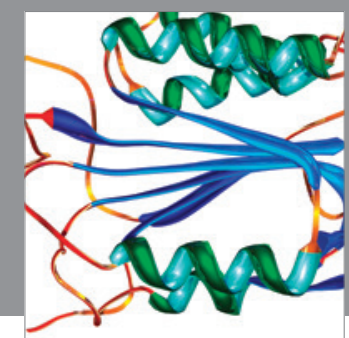

Disease Markers
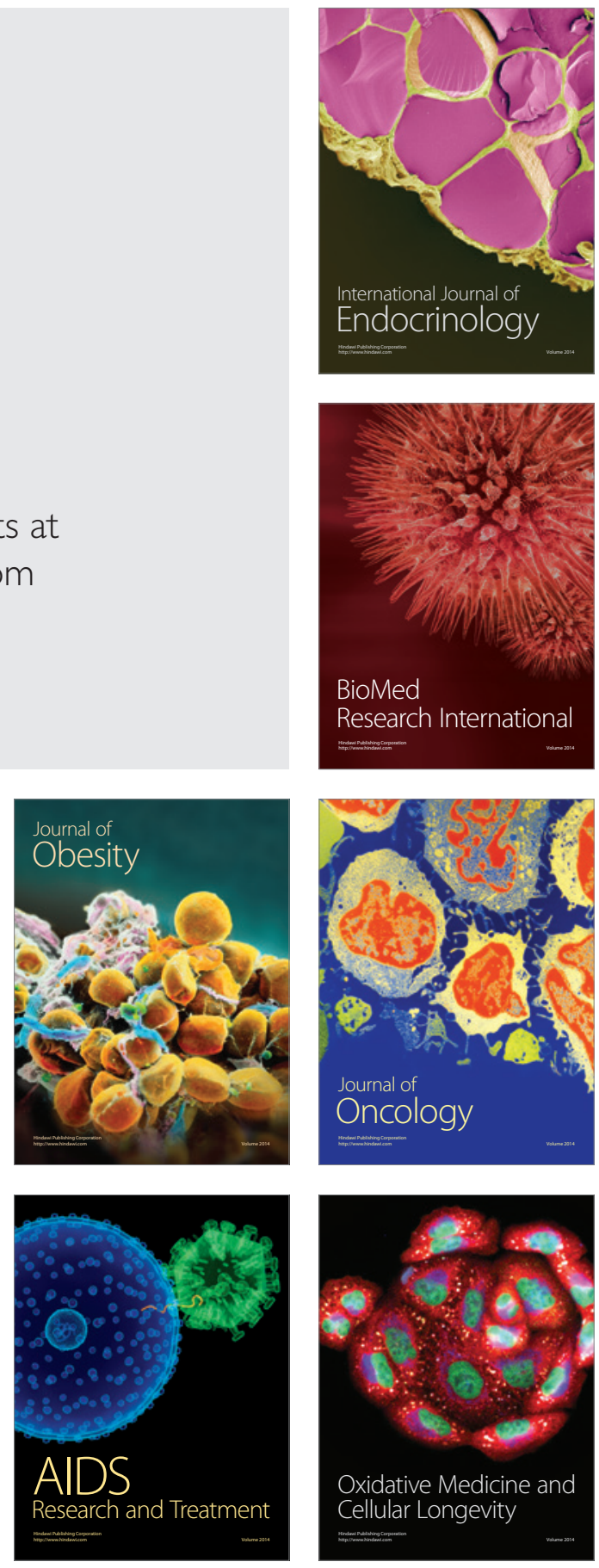